\title{
In Vivo Study of Phytanic Acid $\alpha$-Oxidation in Classic Refsum's Disease and Chondrodysplasia Punctata
}

\author{
HERMAN J. TEN BRINK, DANIELLE S. M. SCHOR, ROBERT M. KOK, FRANS STELLAARD, \\ JOHANNES KNEER, BWEE TIEN POLL-THE, JEAN-MARIE SAUDUBRAY, AND \\ CORNELIS JAKOBS \\ Department of Pediatrics, Free University Hospital, Amsterdam, The Netherlands [H.J.t.B., D.S.M.S., R.M.K., \\ C.J.]; Kinderklinik, Freie Universität Berlin, Berlin, Germany [J.K.]; University Children's Hospital, Het \\ Wilhelmina Kinderziekenhuis, Utrecht, The Netherlands [B.T.P.-T.]; and Clinique Médicale Infantile, Hôpital \\ des Enfants Malades, Paris, France [J.-M.S.]
}

\begin{abstract}
A series of in vivo experiments is described in which $\left[1{ }^{13} \mathrm{C}\right]$ phytanic acid was given as an oral substrate to a healthy subject and two patients showing an impairment in phytanic acid degradation, one with Refsum's disease and one with chondrodysplasia punctata. After intake of the substrate by the control in a dose of $20 \mathrm{mg} /$ $\mathrm{kg}$ body weight, the production of ${ }^{13} \mathrm{CO}_{2}$ was measured in exhaled breath air and the concomitant formation of labeled 2-hydroxyphytanic acid and of pristanic acid was demonstrated by plasma analysis. After application of a substrate dose of $1 \mathrm{mg} / \mathrm{kg}$ body weight to the control, no substantial amounts of ${ }^{13} \mathrm{CO}_{2}$ were measured, whereas time-dependent analysis of labeled 2-hydroxyphytanic acid in plasma yielded a concentration curve superimposed upon the baseline value $(0.2 \mu \mathrm{mol} / \mathrm{L})$ of the unlabeled substance. Phytanic acid accumulated in plasma from the Refsum's disease patient $[649 \mu \mathrm{mol} / \mathrm{L}$, controls $>1$ y $(n=100):<$ $10 \mu \mathrm{mol} / \mathrm{L}$, whereas the pristanic acid concentration was within the control range $[1.4 \mu \mathrm{mol} / \mathrm{L}$, controls $>1$ y $(n=$ 100): $<3 \mu \mathrm{mol} / \mathrm{L}$ ]. Low amounts of 2 -hydroxyphytanic acid were found normally present $[0.04 \mu \mathrm{mol} / \mathrm{L}$, controls $>$ 1 y $(n=11):<0.2 \mu \mathrm{mol} / \mathrm{L}$, and formation of labeled 2hydroxyphytanic acid could not be demonstrated after ingestion of $\left[1{ }^{13} \mathrm{C}\right]$ phytanic acid in a dose of $1 \mathrm{mg} / \mathrm{kg}$ body weight. In addition to phytanic acid accumulation (232 $\mu \mathrm{mol} / \mathrm{L}$ ), the chondrodysplasia punctata patient showed an elevated 2-hydroxyphytanic acid plasma concentration $(0.4$ $\mu \mathrm{mol} / \mathrm{L}$ ), whereas the plasma pristanic acid level was in the control range $(0.7 \mu \mathrm{mol} / \mathrm{L})$. Oral administration of [1${ }^{13}$ Clphytanic acid $(1 \mathrm{mg} / \mathrm{kg}$ body weight) to this patient resulted in a plasma concentration/time profile of labeled 2-hydroxyphytanic acid similar to that of the control. These findings demonstrate that $\alpha$-hydroxylation of phytanic acid is a physiologic process and indicate that Refsum's disease and chondrodysplasia punctata patients have a different ability to convert phytanic acid into 2-hydroxyphytanic acid. (Pediatr Res 32: 566-570, 1992)
\end{abstract}

\section{Abbreviations}

CDP, chondrodysplasia punctata

PFB, pentafluorobenzyl

RCDP, rhizomelic chondrodysplasia punctata

RD, Refsum's disease

TMS, trimethylsilyl

Received November 29, 1991; accepted June 1, 1992

Correspondence and reprint requests: Dr. C. Jakobs, Dept. of Pediatrics, Free University Hospital, De Boelelaan 1117, 1081 HV Amsterdam, The Netherlands.
Phytanic acid (3,7,11,15-tetramethylhexadecanoic acid) is a 20-carbon branched chain fatty acid found only in trace amounts in healthy human beings. Endogenous de novo biosynthesis of phytanic acid has not been demonstrated, and its origin appears to be exclusively exogenous. Dietary intake of the compound itself is the major source of phytanic acid in man, and minor additional amounts may result from dietary phytol. The presence of a 3-methyl group in the phytanic acid molecular structure prohibits its breakdown by $\beta$-oxidation, the usual degradation route for straight-chain fatty acids. Instead, phytanic acid metabolism is believed to involve an initial $\alpha$-hydroxylation and decarboxylation, leading to pristanic acid $(2,6,10,14$-tetramethylpentadecanoic acid), which can be degraded through successive $\beta$-oxidation steps (see Ref. 1 for a review). Phytanic acid was long thought to accumulate only in cases of classic RD. Later, accumulation of phytanic acid was demonstrated to occur in patients suffering from peroxisomal disorders characterized by a general loss of peroxisomal functions, i.e., Zellweger syndrome, infantile RD, neonatal adrenoleukodystrophy, and hyperpipecolic acidemia, and in the rhizomelic form of CDP (see Ref. 2 for a review). In all these disorders, a concomitant impairment of phytanic acid $\alpha$-oxidation was found, usually determined by measurement of ${ }^{14} \mathrm{CO}_{2}$ release after incubation of tissue preparations with $\left[1-{ }^{14} \mathrm{C}\right]$ phytanic acid.

Studies on rat liver homogenates incubated with radioactively labeled phytanic acid have shown the presence of labeled 2hydroxyphytanic acid, indicating that in mammals $\alpha$-hydroxylation is the first step in the phytanic acid $\alpha$-oxidation (3-6). This leads to the proposed pathway for degradation of phytanic acid shown in Figure 1. The occurrence of this pathway in man has been confirmed in tissue cultures of skin fibroblasts $(3,7)$. The finding that i.v. injected $\left[\mathrm{U}-{ }^{14} \mathrm{C}\right] 2$-hydroxyphytanic acid was metabolized rapidly in healthy humans and also in RD patients provided evidence that the biochemical defect in $\mathrm{RD}$ is a deficient $\alpha$-hydroxylation of phytanic acid (8). However, in vivo studies in man confirming the direct formation of 2-hydroxyphytanic acid from phytanic acid have not been reported, and recently the formation of 2-hydroxyphytanic acid as an intermediate in the phytanic acid metabolism was questioned (9).

In our investigation of phytanic acid $\alpha$-oxidation in man, we developed an alternative in vivo approach, consisting of oral administration of $\left[1-{ }^{13} \mathrm{C}\right]$ phytanic acid to a healthy control and to selected patients with a deficiency in phytanic acid $\alpha$-oxidation and measurement of accordingly labeled metabolites. To assess experimental conditions for approximation of a physiologic sit- 


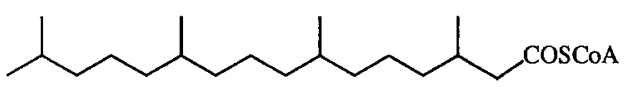

phytanic acid

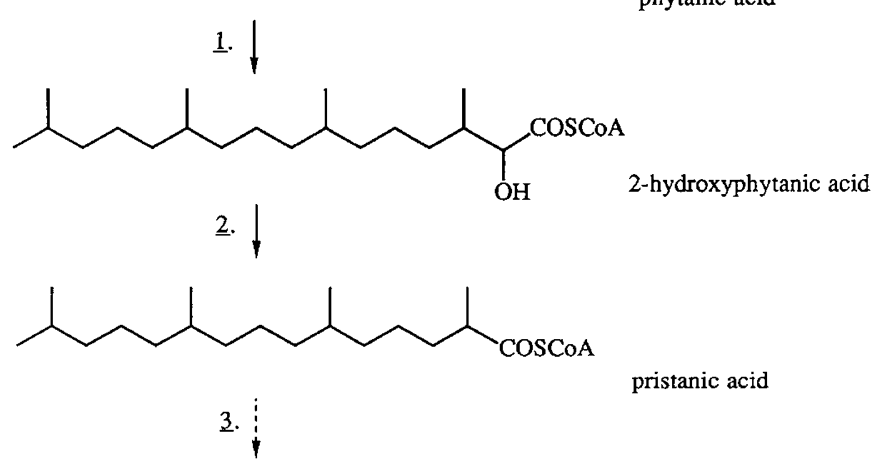

Fig. 1. Metabolism of phytanic acid. $1, \alpha$-hydroxylation; 2, decarboxylation; and $3, \beta$-oxidation.

uation, the substrate was first given in two different dosages to a healthy volunteer. Thereupon an amount of the substrate considered sufficient to detect labeled degradation products in plasma was given to a classic RD patient and a CDP patient. The finding of severe phytanic acid accumulation combined with normal pristanic acid levels in plasma from such patients indicates that in these disorders the metabolic defect in the degradation pathway of phytanic acid is situated within its $\alpha$-oxidation (10). In $\mathrm{RD}$, a deficient $\alpha$-hydroxylation of phytanic acid is supposed to be the only biochemical abnormality $(7,8)$. In the rhizomelic form of CDP, an impaired plasmalogen biosynthesis and the occurrence of an unprocessed peroxisomal 3-oxoacylCoA thiolase are found next to an impaired phytanic acid $\alpha$ oxidation (11). Studies on phytanic acid $\alpha$-oxidation by complementation analysis of $\mathrm{RD}$ and peroxisomal disorders revealed that RD and RCDP represent different complementation groups, indicating that the enzyme defect in RCDP involves a different step in the phytanic acid $\alpha$-oxidation from that of the defect in RD (12).

The present study was undertaken to investigate whether differences in phytanic acid degradation deficiency would be discernible by detection of specific metabolites. A preliminary report of a part of this work has been published before (13).

\section{MATERIALS AND METHODS}

Patients. Patient 1 is a classic RD patient, 35 y of age. Phytanic acid $\alpha$-oxidation in skin fibroblasts was $5 \%$ of control. Plasma phytanic acid concentration was $649 \mu \mathrm{mol} / \mathrm{L}$ [controls $>1$ y $(n$ $=100):<10 \mu \mathrm{mol} / \mathrm{L}]$; plasma pristanic acid concentration was $1.4 \mu \mathrm{mol} / \mathrm{L}$ [controls $>1$ y $(n=100):<3 \mu \mathrm{mol} / \mathrm{L}]$. Patient 2 is a 13-mo-old nonrhizomelic CDP patient, biochemically indistinguishable from the classic RCDP phenotype, with impaired phytanic acid $\alpha$-oxidation capacity (residual activity $1.6 \%$ of control), impaired plasmalogen biosynthesis, and 3-oxoacyl-CoA thiolase in the unprocessed form. A case report has been published (14). Plasma phytanic acid concentration was $232 \mu \mathrm{mol} /$ $\mathrm{L}$; plasma pristanic acid concentration was $0.7 \mu \mathrm{mol} / \mathrm{L}$. The control person is a man, $31 \mathrm{y}$ of age, without signs of any disease. Informed consent was obtained from patient 1 and the control, and from the parents of patient 2.

Materials. Phytol was purchased from Merck (Darmstadt, Germany), $\left[{ }^{13} \mathrm{C}\right]$ sodium cyanide $\left(99.2\right.$ atom $\left.\%{ }^{13} \mathrm{C}\right)$ was from Merck Sharp \& Dohme (Montreal, Canada), and pentafluorobenzyl bromide was obtained from Pierce (Rockford, IL). Organic solvents and reagents were of analytical grade and unless stated otherwise were used without further purification.

Phytanic acid was prepared from phytol by following a published method (15). For the preparation of $\left[1-{ }^{13} \mathrm{C}\right]$ phytanic acid $\left(99\right.$ atom $\%{ }^{13} \mathrm{C}$ ) from unlabeled phytanic acid, a prescribed synthesis of $\left[1-{ }^{14} \mathrm{C}\right]$ phytanic acid (16) with some modifications was applied (13). The product was purified by column chromatography over silica gel, using a gradient of hexane and ethyl acetate that had been freshly distilled.

Unlabeled 2-hydroxyphytanic acid was synthesized from phytanic acid. Bromine was introduced into the $\alpha$-position by HellVolhard-Zelinsky reaction (17), and ethanolysis of the reaction mixture yielded 2-bromophytanic acid ethyl ester. Bromide was substituted by acetate using sodium acetate in DMSO, and the resulting diester was saponified with $\mathrm{KOH}$ in ethanol, giving 2hydroxyphytanic acid after acidification.

In an analogous manner, [3-methyl- ${ }^{2} \mathrm{H}_{3}$ ]2-hydroxyphytanic acid (99 atom $\%{ }^{2} \mathrm{H}_{3}$ ) was synthesized from [3-methyl- ${ }^{2} \mathrm{H}_{3}$ ] phytanic acid. The synthesis of this latter compound, together with that of $\left[2-\right.$ methyl $\left.-{ }^{2} \mathrm{H}_{3}\right]$ pristanic acid, has been published before (18).

Administration of $\left[1-{ }^{13} \mathrm{C}\right]$ phytanic acid. In two separate experiments, $\left[1-{ }^{13} \mathrm{C}\right]$ phytanic acid was given to the healthy volunteer. After a fasting period of $12 \mathrm{~h}$, the free acid, soaked in a piece of bread, was administered orally in doses of 20 and $1 \mathrm{mg} / \mathrm{kg}$ body weight, respectively. Subsequently, the RD patient and the CDP patient (also after $12 \mathrm{~h}$ fasting) received the dose of $1 \mathrm{mg} / \mathrm{kg}$ body weight, which was appropriate to allow the detection of reliably measurable amounts of parent compound and metabolites in plasma. Administration of the substrate to the RD patient was as to the control. For the CDP patient, the substrate was embedded in a small amount of fruit yogurt, and complete intake was carefully controlled. For the control person, exhaled breath air was collected every $15 \mathrm{~min}$ during the first $4 \mathrm{~h}$, every $30 \mathrm{~min}$ during the next $4 \mathrm{~h}$, and subsequently every hour during $4 \mathrm{~h}$. Two additional breath samples were taken after 24 and $26 \mathrm{~h}$. After initial blood sampling $1 \mathrm{~h}$ after administration, blood samples were taken every $2 \mathrm{~h}$ during the first $13 \mathrm{~h}$ of the experimental period.

Measurement of exhaled $\mathrm{CO}_{2}$. Exhaled $\mathrm{CO}_{2}$ in breath air samples was purified by following a standard kryogenic procedure (19). The isotopic enrichment of the purified $\mathrm{CO}_{2}(\delta \Delta$ values) was determined by isotope ratio mass spectrometric measurement of $\mathrm{m} / \mathrm{z} 44$ and 45 . Cumulative output of ${ }^{13} \mathrm{CO}_{2}(\%$ of dose) was calculated and corrected for normal endogenous $\mathrm{CO}_{2}$ production, which was determined independently.

Plasma analysis. Analyses of pristanic acid and unlabeled and labeled phytanic and 2-hydroxyphytanic acids were performed in $200-\mu \mathrm{L}$ plasma aliquots. After addition of the internal standards $\left(0.5 \mathrm{nmol}\right.$ of $\left[2-\right.$ methyl- $\left.{ }^{2} \mathrm{H}_{3}\right]$ pristanic acid, $2 \mathrm{nmol}$ of [3methyl- $-{ }^{2} \mathrm{H}_{3}$ ]phytanic acid and 0.05 nmol of $\left[3-\right.$ methyl- $\left.{ }^{2} \mathrm{H}_{3}\right] 2-$ hydroxyphytanic acid), the samples were hydrolyzed by first adding $2.0 \mathrm{~mL} 0.5 \mathrm{M} \mathrm{HCl} /$ acetonitrile and heating for $45 \mathrm{~min}$ at $100^{\circ} \mathrm{C}$, followed by adding $2.0 \mathrm{~mL} 1 \mathrm{M} \mathrm{NaOH} /$ methanol and heating for $45 \mathrm{~min}$ at $100^{\circ} \mathrm{C}$. The cooled solutions were acidified with $6 \mathrm{M} \mathrm{HCl}$ to $\mathrm{pH} 1$ and extracted with $3 \times 3 \mathrm{~mL}$ hexane. The combined hexane extracts were evaporated to dryness at $40^{\circ} \mathrm{C}$ under a stream of nitrogen. Carboxylic acids were converted to their PFB esters by treating the residue with $100 \mu \mathrm{L} \mathrm{7 \%} \mathrm{PFB-}$ $\mathrm{Br}$ /acetonitrile and $10 \mu \mathrm{L}$ triethylamine for $15 \mathrm{~min}$ at room temperature. After adding $150 \mu \mathrm{L} 0.5 \mathrm{M} \mathrm{HCl}$, the PFB esters were extracted into $1 \mathrm{~mL}$ hexane, and $2 \mu \mathrm{L}$ of this hexane fraction were used for gas chromatography-mass spectrometry analysis of pristanic acid and phytanic acid (10).

For plasma analysis of free labeled and unlabeled phytanic acid, the hydrolytic steps were omitted: after addition of the internal standard (2 nmol of [3-methyl ${ }^{2} \mathrm{H}_{3}$ ]phytanic acid), plasma samples were acidified to $\mathrm{pH} 1$. Further extraction and derivatization steps were identical to those described above.

Before analysis of 2-hydroxyphytanic acid, the remaining hexane extract was purified over a silica solid phase extraction column (volume $2.8 \mathrm{~mL}$, Bond Elut, Analytichem International, Inc., Harbor City, CA). The column was solvated with $10 \mathrm{~mL}$ hexane, and the crude extract containing PFB esters was introduced onto the column. After rinsing with $2 \mathrm{~mL}$ hexane and 10 $\mathrm{mL} 1 \%$ ethylacetate/hexane, the elution was performed with 10 
$\mathrm{mL} 5 \%$ ethylacetate/hexane. The eluent was evaporated to dryness at $40^{\circ} \mathrm{C}$ under a stream of nitrogen. Hydroxyl groups were derivatized by adding $100 \mu \mathrm{L}$ bis-trimethylsilyltrifluoroacetamide and $100 \mu \mathrm{L}$ pyridine to the residue and heating for $60 \mathrm{~min}$, at $80^{\circ} \mathrm{C}$. From this mixture, $2 \mu \mathrm{L}$ were used for gas chromatography-mass spectrometry analysis of 2-hydroxyphytanic acid.

Gas chromatographic separation was performed using a CPSil 19 CB capillary column (Chrompack, Middelburg, The Netherlands). Pristanic, phytanic, and 2-hydroxyphytanic acids were measured by applying electron capture negative chemical ionization mass fragmentography. Selected ion monitoring of carboxylate anion fragments with $-\mathrm{m} / \mathrm{z}$ values of 297 (pristanate), 311,312 (phytanate), 399, and 400 (TMS-2-hydroxyphytanate) was carried out, and compounds were quantitated relative to their ${ }^{2} \mathrm{H}_{3}$-labeled internal standards $(-\mathrm{m} / \mathrm{z} 300,314$, and 402 , respectively). When relevant, ion peak areas of substances to be measured were corrected for interference of natural occurring isotope abundances of their unlabeled analogues.

Identification of peaks attributed to 2-hydroxyphytanic acid was verified by gas chromatography of its TMS-PFB derivative using a CP-Sil $88 \mathrm{CB}$ column. In addition, the 2-O-acetyl derivative of 2-hydroxyphytanic acid PFB ester was prepared by adding $100 \mu \mathrm{L}$ acetic anhydride and $100 \mu \mathrm{L}$ pyridine to the residue containing PFB esters and heating for $60 \mathrm{~min}$ at $80^{\circ} \mathrm{C}$. After evaporation under a stream of nitrogen, the residue was taken up in $100 \mu \mathrm{L}$ hexane, and from this mixture $2 \mu \mathrm{L}$ were used for separation on a CP-Sil 19 column and measurement at $-\mathrm{m} / \mathrm{z} 369,370$, and 372 (2-O-acetyl-2-hydroxyphytanate).

\section{RESULTS}

In the first experiment, $\left[1-{ }^{13} \mathrm{C}\right]$ phytanic acid was given to a healthy subject in a dose of $20 \mathrm{mg} / \mathrm{kg}$ body weight. Figure 2 shows the resulting ${ }^{13} \mathrm{CO}_{2}$ enrichment in exhaled breath air, plotted versus time. Labeled $\mathrm{CO}_{2}$ was recovered in the subject's breath already $1 \mathrm{~h}$ after administration of the substrate. The levels of exhaled ${ }^{13} \mathrm{CO}_{2}$ reached a broad maximum between 5 and $15 \mathrm{~h}$ and appeared to decrease slowly after that. The cumulative ${ }^{13} \mathrm{CO}_{2}$ output during the observation period reached only approximately $30 \%$ of the substrate dose, without reaching a plateau. This picture is in accordance with analyses of substrate and metabolites in plasma, which are depicted in Figure 3. Within $1 \mathrm{~h}$ after administration of $\left[1{ }^{13} \mathrm{C}\right]$ phytanic acid, the plasma concentration of the substrate exceeded the normal level

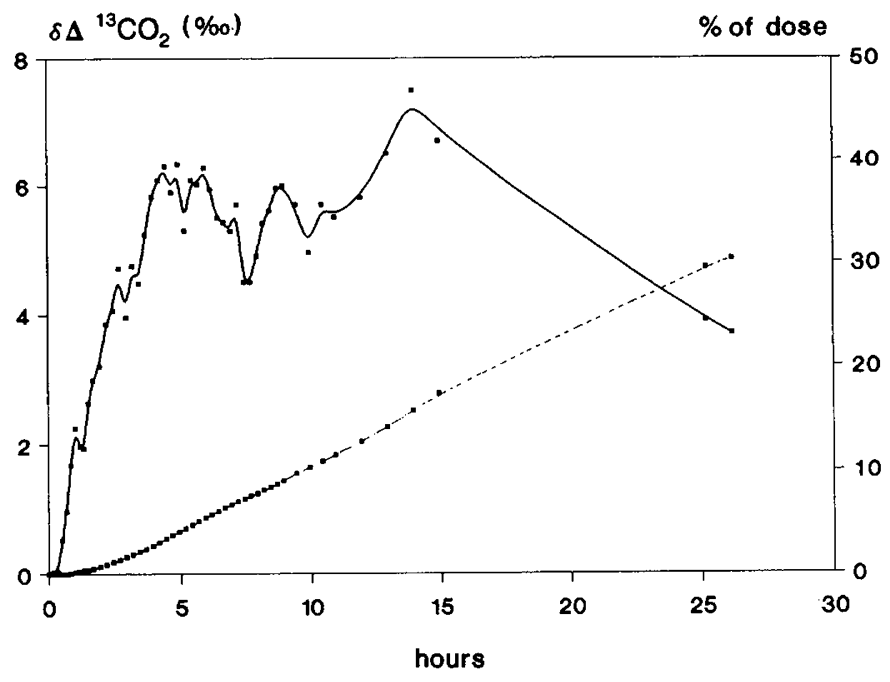

- enrichment $\cdots$-... cumulative output

Fig. 2. Enrichment $(\delta \Delta, \%$ ) and cumulative output (\% of dose) of ${ }^{13} \mathrm{CO}_{2}$ in exhaled breath air after administration of $\left[1-{ }^{13} \mathrm{C}\right]$ phytanic acid ( $20 \mathrm{mg} / \mathrm{kg}$ body weight) to a healthy individual.

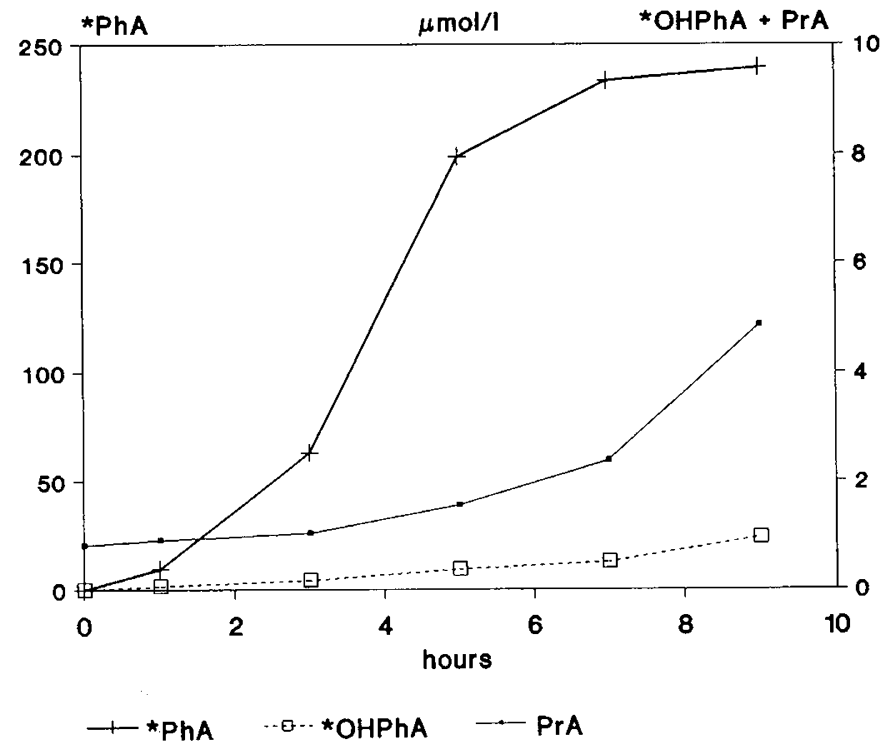

Fig. 3. Concentrations $(\mu \mathrm{mol} / \mathrm{L})$ of substrate $\left({ }^{*} P h A\right)$, labeled 2-hydroxyphytanic acid $\left({ }^{*} O H P h A\right)$, and pristanic acid $(\operatorname{Pr} A)$ in plasma after administration of $\left[1-{ }^{13} \mathrm{C}\right]$ phytanic acid $(20 \mathrm{mg} / \mathrm{kg}$ body weight) to a healthy individual.

of phytanic acid [which had a constant value of $5 \mu \mathrm{mol} / \mathrm{L}$ (controls $>1$ y $(n=100):<10.0 \mu \mathrm{mol} / \mathrm{L})$ during the experiment]. The substrate dose resulted in a total plasma concentration of labeled and unlabeled phytanic acid of more than 200 $\mu \mathrm{mol} / \mathrm{L}$.

Unlabeled 2-hydroxyphytanic acid was detected in plasma by measurement of ion intensities at $-\mathrm{m} / \mathrm{z} 399$, giving a constant concentration of $0.10 \mu \mathrm{mol} / \mathrm{L}$ during the experiment [controls $>1$ y $(n=11):$ mean $=0.10 \pm 0.04 \mu \mathrm{mol} / \mathrm{L}$ (range: $0.02-0.20$ $\mu \mathrm{mol} / \mathrm{L})]$. An increasing response at $-\mathrm{m} / \mathrm{z} 400$ was measured with time, to be attributed to increasing concentrations of labeled 2-hydroxyphytanic acid. Plasma concentrations of the metabolite were too low to permit full positive identification by scanning mode mass spectrometry. However, the peak in the plasma samples was indistinguishable from that of the reference compound when analyzed on both a CP-Sil 19 and a CP-Sil 88 gas chromatography column. Also, when the 2-O-acetyl derivative was measured instead of the 2-O-TMS derivative, the peaks were identical using a CP-Sil 19 column, and the same quantitative results were obtained.

The $\alpha$-oxidation of $\left[1-{ }^{13} \mathrm{C}\right]$ phytanic acid is expected to result in formation of unlabeled pristanic acid. Consequently, a concomitant rise of plasma pristanic acid concentrations was observed after administration of the substrate in a dose of $20 \mathrm{mg} /$ $\mathrm{kg}$ body weight, eventually exceeding control levels [controls $>$ $1 \mathrm{y}(n=100):<3.0 \mu \mathrm{mol} / \mathrm{L}]$. Concentrations of the substrate and its metabolites did not return to their baseline values during the observation period (Fig. 3).

In the second control experiment, the dose of $\left[1-{ }^{13} \mathrm{C}\right]$ phytanic acid was diminished to $1 \mathrm{mg} / \mathrm{kg}$ body weight. Analysis of exhaled breath air revealed no substantial increase of ${ }^{13} \mathrm{CO}_{2}$ concentration. An initial increase of plasma substrate concentration was followed by a decrease after $\sim 6 \mathrm{~h}$, the maximum level $(6 \mu \mathrm{mol} /$ L) now remaining within the physiologic range. The plasma pristanic acid and 2-hydroxyphytanic acid concentrations remained constant $(2.6$ and $0.2 \mu \mathrm{mol} / \mathrm{L}$, respectively).

The CDP and the RD patients were equally dosed with $1 \mathrm{mg} /$ $\mathrm{kg}$ body weight of the substrate. Because of the strongly elevated plasma phytanic acid levels [RD: $649 \mu \mathrm{mol} / \mathrm{L}$; CDP: $232 \mu \mathrm{mol} /$ $\mathrm{L}$; controls $>1$ y $(n=100):<10 \mu \mathrm{mol} / \mathrm{L}]$ upon which substrate levels would be superimposed, the appearance of the substrate after its ingestion could not be demonstrated by measurement of total plasma phytanic acid. However, the substrate could be detected in the plasma from both patients by measurement of 
phytanic acid present as free acid, after omitting the hydrolytic steps in the analytical procedure. Free, unlabeled phytanic acid was present and elevated in plasma from both patients [RD: 23 $\mu \mathrm{mol} / \mathrm{L}$; CDP: $13 \mu \mathrm{mol} / \mathrm{L}$; controls $>1 \mathrm{y}(n=20)$ : mean $=0.18$ $\pm 0.20 \mu \mathrm{mol} / \mathrm{L}$ (range: $0.02-0.86 \mu \mathrm{mol} / \mathrm{L}$ )], but levels were sufficiently low to allow reliable quantitation of the labeled substrate in its free acid form. The resulting substrate curves for the patients and the control are presented in Figure 4.

In Figure 5, the analysis of labeled 2-hydroxyphytanic acid in plasma from the control and the patients is depicted. The appearance of this acid in plasma from the control and the CDP patient after the intake of the substrate could be clearly shown. The curves reached a maximum after 7-9 h, and, even $1 \mathrm{~d}$ after administration of the substrate, appreciable amounts of labeled 2 -hydroxyphytanic acid were still measurable. In plasma from the RD patient, minute amounts of labeled 2-hydroxyphytanic acid were detectable after administration of the substrate, but concentrations did not show an increase as observed in plasma from the control and the CDP patient.

Concentrations of unlabeled 2-hydroxyphytanic acid in plasma

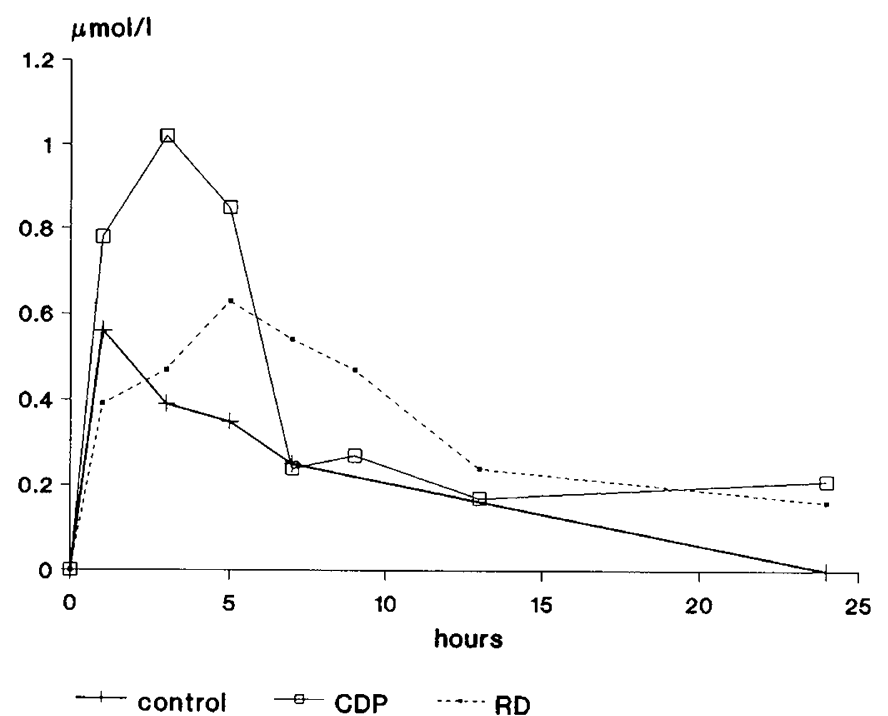

Fig. 4. Concentrations $(\mu \mathrm{mol} / \mathrm{L})$ of free substrate in plasma after administration of $\left[1-{ }^{13} \mathrm{C}\right]$ phytanic acid ( $1 \mathrm{mg} / \mathrm{kg}$ body weight) to a CDP patient, an RD patient, and a healthy individual.

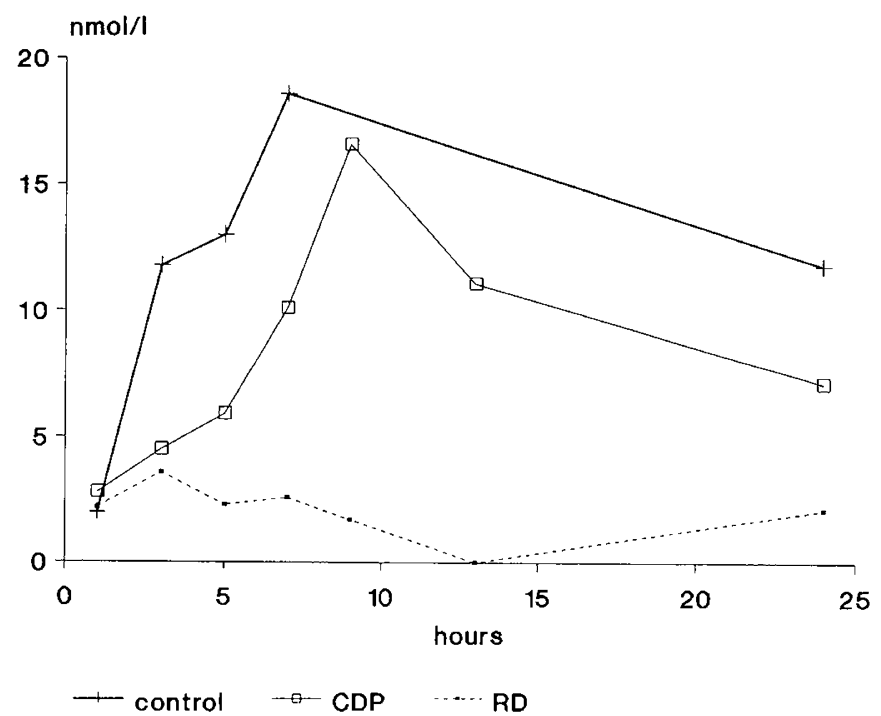

Fig. 5. Concentrations ( $\mathrm{nmol} / \mathrm{L}$ ) of labeled 2-hydroxyphytanic acid in plasma after administration of $\left[1-{ }^{13} \mathrm{C}\right]$ phytanic acid $(1 \mathrm{mg} / \mathrm{kg}$ body weight) to a CDP patient, an RD patient, and a healthy individual. from the RD patient and the CDP patient were 0.04 and 0.4 $\mu \mathrm{mol} / \mathrm{L}$, respectively [controls $>1$ y $(n=11): 0.10 \pm 0.04 \mu \mathrm{mol} /$ L (range: $0.02-0.20 \mu \mathrm{mol} / \mathrm{L}$ )], whereas plasma pristanic acid concentrations were 1.4 and $0.7 \mu \mathrm{mol} / \mathrm{L}$, respectively, during the experiment.

\section{DISCUSSION}

It has been well established that the human metabolism of phytanic acid involves an initial $\alpha$-cleavage leading to pristanic acid and $\mathrm{CO}_{2}$. Based upon studies with experimental animals and human cell material, the conclusion was drawn that in mammals 2-hydroxyphytanic acid is the first metabolite in phytanic acid $\alpha$-oxidation. Though these results look convincing, a direct proof of the physiologic formation of 2-hydroxyphytanic acid originating from phytanic acid has not been given.

We considered that the use of stable isotopically labeled phytanic acid given orally to a healthy control person, followed by mass spectrometric detection of specific metabolites, might elucidate some relevant details in human phytanic acid $\alpha$-oxidation. Applied to selected patients showing accumulation of phytanic acid in their plasma due to a limited capability to degrade this acid, this approach was envisaged to reveal where a possible enzyme defect in the $\alpha$-oxidation of phytanic acid might be located.

In this article, we describe a series of in vivo experiments in which $\left[1-{ }^{13} \mathrm{C}\right]$ phytanic acid was given as an oral substrate to a healthy control subject, an RD patient, and a CDP patient, followed by the identification of degradation products: ${ }^{13} \mathrm{CO}_{2}$ in exhaled breath air, and pristanic acid and labeled phytanic and 2-hydroxyphytanic acids in plasma.

In the first control experiment, $\left[1-{ }^{13} \mathrm{C}\right]$ phytanic acid was given in a dose of $20 \mathrm{mg} / \mathrm{kg}$ body weight. The quick rise of the plasma substrate concentration after ingestion indicates a rapid absorption and systemic availability. The resulting height of the substrate concentration resembles levels usually observed in plasma from patients who severely accumulate this acid (10). However, intake of the labeled substrate in this dose did not influence the plasma concentrations of unlabeled phytanic acid and 2-hydroxyphytanic acid normally present.

The detection of increasing amounts of labeled 2-hydroxyphytanic acid as a direct consequence of the intake of labeled phytanic acid clearly demonstrates the involvement of the former acid in the phytanic acid $\alpha$-oxidation. The concomitant increase of plasma pristanic acid further confirms the involvement of a decarboxylation step in the human phytanic acid metabolism. Breath analysis in this experiment demonstrated that the substrate was degraded with the release of ${ }^{13} \mathrm{CO}_{2}$. Its production started within $1 \mathrm{~h}$ after ingestion of the substrate and reached a plateau level of several hours duration. Even after $1 \frac{1 / 2}{d}$, only $30 \%$ of the total dose had been metabolized, and still relatively high amounts of ${ }^{13} \mathrm{CO}_{2}$ were found. It seems that this dose caused a substantial overload of the body capacity to break down phytanic acid, leading to incorporation of $\left[1-{ }^{13} \mathrm{C}\right]$ phytanic acid in adipose tissue from which it is only slowly released.

In the second control experiment, the dose of $\left[1-{ }^{13} \mathrm{C}\right]$ phytanic acid was diminished to $1 \mathrm{mg} / \mathrm{kg}$ body weight. This dose corresponds to the amount of phytanic acid present in an ordinary diet, estimated at $50-100 \mathrm{mg} / \mathrm{d}$ (1). Plasma concentrations of the substrate now remained within a physiologic range. The concomitant rise and decline of labeled 2-hydroxyphytanic acid concentrations confirms that hydroxylation of phytanic acid is a physiologic process and was not provoked as an escape route, which would have been possible when applying a high substrate dose as in the first experiment. The capacity of the body to metabolize phytanic acid was not stressed by the intake of the substrate as became also apparent from the absence of an increase of pristanic acid plasma concentrations. Our findings clearly demonstrate that 2-hydroxyphytanic acid is an obligatory intermediate in the degradation of phytanic acid. 
Considering the results above, a substrate dose of $1 \mathrm{mg} / \mathrm{kg}$ body weight was envisaged to be appropriate for administration to the patients. As no significant ${ }^{13} \mathrm{CO}_{2}$ enrichment was observed in exhaled breath air from the control subject after this dose, no attempts were made to perform breath analysis from the patients, and the decision was made to confine to plasma analysis. Despite the different ages of the control and the CDP patient, levels of substrate and metabolites in plasma from both patients can reliably be compared with those in plasma from the control, as the age-dependency observed for phytanic and pristanic acid concentrations is only relevant at ages $<12$ mo (10).

When total plasma phytanic acid was measured, the height of the phytanic acid concentrations in plasma from both patients prevented a reliable quantitation of substrate concentrations, which were expected to contribute very little to the accumulating phytanic acid. However, measurement of free phytanic acids demonstrated a proper intake of the substrate. It is interesting to note that an equivalent loading dose on the basis of body weight resulted in plasma substrate curves with (although individual values were varying) estimated areas comparable for both patients. However, analysis of labeled 2-hydroxyphytanic acid revealed a marked difference between the RD patient and the CDP patient. The absence of a concentration curve of labeled 2hydroxyphytanic acid in plasma from the RD patient correlates well with the proposed defect in this disorder. Comparison of the concentration patterns of labeled 2-hydroxyphytanic acid in plasma from the control and in that from the CDP patient demonstrates a similar response upon intake of $\left[1-{ }^{13} \mathrm{C}\right]$ phytanic acid, indicating a comparable ability to hydroxylate phytanic acid. Also, the finding that the unlabeled 2-hydroxyphytanic acid level in plasma from the RD patient was low within the control range, whereas in plasma from the CDP patient it was elevated, is indicative of a dissimilar phytanic acid $\alpha$-oxidation deficiency in RD and CDP.

There is a controversy as to the exact location of phytanic acid $\alpha$-oxidation. Although phytanic acid $\alpha$-oxidation is impaired in generalized peroxisomal disorders, suggesting that peroxisomes are involved in this process, recent findings suggest that phytanic acid $\alpha$-oxidation takes place in mitochondria, not in peroxisomes $(20,21)$. Next to an impaired phytanic acid degradation, one of the characteristic features in the rhizomelic form of CDP is a deficient plasmalogen biosynthesis, which is considered a parameter for peroxisomal disease. However, if phytanic acid $\alpha$ oxidation appears to be a mitochondrial process, the question remains how an impaired $\alpha$-oxidation of phytanic acid and peroxisomal dysfunction in CDP are related. Maybe the first step in phytanic acid $\alpha$-oxidation requires mitochondria, and the second step peroxisomes. Our findings suggest that in CDP the defect in the $\alpha$-oxidation of phytanic acid is located in its second step, that is the conversion of 2-hydroxyphytanic acid into pristanic acid.

In this context, the possibility that 2-oxophytanic acid is an intermediate in the conversion of 2-hydroxyphytanic acid to pristanic acid cannot be ruled out. Recently, in rat kidney cortex, the formation of 2-oxophytanic acid was observed as a product of the peroxisomal oxidation of 2-hydroxyphytanic acid $(22,23)$. The relevance of this finding for human phytanic acid degradation, however, remains to be established.

\section{REFERENCES}

1. Steinberg D 1989 Refsum disease. In: Scriver CR, Beaudet AL, Sly WS, Valle $\mathrm{D}$ (eds) The Metabolic Basis of Inherited Disease. McGraw-Hill, New York, pp 1533-1550

2. Lazarow PB, Moser HW 1989 Disorders of peroxisome biogenesis. In: Scriver CR, Beaudet AL, Sly WS, Valle D (eds) The Metabolic Basis of Inherited Disease. McGraw-Hill, New York, pp 1479-1509

3. Tsai S-C, Herndon Jr JH, Uhlendorf BW, Fales HM, Mize CE 1967 The formation of alpha-hydroxy phytanic acid from phytanic acid in mammalian tissues. Biochem Biophys Res Commun 28:571-577

4. Tsai S-C, Avigan J, Steinberg D 1969 Studies on the $\alpha$-oxidation of phytanic acid by rat liver mitochondria. J Biol Chem 244:2682-2692

5. Muralidharan FN, Muralidharan VB 1987 Phytanic acid alpha oxidation in rat liver: studies on alpha hydroxylation. Int J Biochem 19:663-670

6. Mize CE, Avigan J, Steinberg D, Pittman RC, Fales HM, Milne GWA 1969 A major pathway for the mammalian oxidative degradation of phytanic acid. Biochim Biophys Acta 176:720-739

7. Herndon JH, Steinberg D, Uhlendorf W, Fales HM 1969 Refsum's disease: characterization of the enzyme defect in cell culture. J Clin Invest 48:10171032

8. Mize CE, Herndon JH, Blass JP, Milne GWA, Follansbee C, Laudat P Steinberg D 1969 Localization of the oxidative defect in phytanic acid degradation in patients with Refsum's disease. J Clin Invest 48:1033-1040

9. Skjeldal OH, Stokke O 1988 Evidence against $\alpha$-hydroxyphytanic acid as an intermediate in the metabolism of phytanic acid. Scand J Clin Lab Invest 48:97-102

10. ten Brink HJ, Stellaard F, van den Heuvel CMM, Kok RM, Schor DSM, Wanders RJA, Jakobs C 1992 Pristanic acid and phytanic acid in plasma from patients with peroxisomal disorders: stable isotope dilution analysis with electron capture negative ion mass fragmentography. J Lipid Res 33:4147

11. Hoefler G, Hoefler S, Watkins PA, Chen WW, Moser A, Baldwin V, McGillivary B, Charrow J, Friedman JM, Rutledge L, Hashimoto T, Moser HW 1988 Biochemical abnormalities in rhizomelic chondrodysplasia punctata. J Pediatr 112:726-733

12. Poll-The BT, Skjeldal OH, Stokke O, Poulos A, Demaugre F, Saudubray JM 1989 Phytanic acid alpha-oxidation and complementation analysis of classical Refsum and peroxisomal disorders. Hum Genet 81:175-181

13. ten Brink HJ, Stellaard F, Jakobs C 1990 In vivo use of stable isotopes in the study of phytanic acid metabolism. In: Chapman TE, Berger R, Reyngoud DJ, Okken A (eds) Stable Isotopes in Paediatric, Nutritional and Metabolic Research. Intercept, Andover, UK, pp 257-262

14. Poll-The BT, Maroteaux P, Narcy C, Quetin P, Guesnu M, Wanders RJA, Schutgens RBH, Saudubray JM 1991 A new type of chondrodysplasia punctata associated with peroxisomal dysfunction. J Inher Metab Dis 14:361-363

15. Jellum E, Eldjarn L, Try K 1966 Conversion of phytol into dihydrophytol and phytanic acid. Acta Chem Scand 20:2535-2538

16. Poulos A, Barone E, Johnson DW 1980 Partial synthesis of $\left[1-{ }^{14} \mathrm{C}\right]$ phytanic acid. Lipids 15:19-21

17. Mendel H, Coops J 1939 The gradual decomposition by oxidation of fatty acids into their next lower homologues. Recl Trav Chim Pays-Bas 58:11331143

18. ten Brink HJ, Jakobs C, van der Baan JL, Bickelhaupt F 1989 Synthesis of deuterium labelled analogues of pristanic acid and phytanic acid for use as internal standards in stable isotope dilution analysis. In: Baillie TA, Jones JR (eds) Synthesis and Applications of Isotopically Labelled Compounds 1988. Elsevier, Amsterdam, pp 717-722

19. Schoeller DA, Klein PD 1978 A simplified technique for collecting breath $\mathrm{CO}_{2}$ for isotope ratio mass spectrometry. Biomed Mass Spectrom 5:29-31

20. Skjeldal OH, Stokke O 1987 The subcellular localization of phytanic acid oxidase in rat liver. Biochim Biophys Acta 921:38-42

21. Watkins PA, Mihalik SJ, Skjeldal OH 1990 Mitochondrial oxidation of phytanic acid in human and monkey liver: implication that Refsum's disease is not a peroxisomal disorder. Biochem Biophys Res Commun 167:580-586

22. Draye JP, van Hoof F, de Hoffmann E, Vamecq J 1987 Peroxisomal oxidation of L-2-hydroxyphytanic acid in rat kidney cortex. Eur J Biochem 167:573578

23. Vameca J, Draye JP 1988 The enzymatic and mass spectrometric identification of 2-oxophytanic acid, a product of the peroxisomal oxidation of L-2hydroxyphytanic acid. Biomed Environ Mass Spectrom 15:345-351 